\title{
CRKL and CK2 $\beta$ over Expression Are Independent Predictors of Patients Survival in Endometrioid Endometrial Carcinoma
}

\author{
Randa Mohamed Kaf', Wafaa El-Beshbishi' ${ }^{2}$, Ahmed A. Obaya ${ }^{3}$, Rham Z. Ahmed ${ }^{4}$, \\ Khaled Fathy Helal', Mohamed SH. Ramadan', Abdelwahab S. Almoregy6, \\ Ibrahim A. Heggy6, Ola A. Harb ${ }^{*}$
}

\author{
${ }^{1}$ Department of Pathology, Faculty of Medicine, Zagazig University, Zagazig, Egypt \\ ${ }^{2}$ Department of Clinical Oncology and Nuclear Medicine, Faculty of Medicine, Mansoura University, Mansoura, Egypt \\ ${ }^{3}$ Department of Clinical Oncology and Nuclear Medicine, Faculty of Medicine, Zagazig University, Zagazig, Egypt \\ ${ }^{4}$ Department of Medical Oncology, Faculty of Medicine, Zagazig University, Zagazig, Egypt \\ ${ }^{5}$ Department of Gynecology \& Obstetrics, Faculty of Medicine, Zagazig University, Zagazig, Egypt \\ ${ }^{6}$ Department of General Surgery, Faculty of Medicine, Zagazig University, Zagazig, Egypt \\ Email: *olaharb2015@gmail.com
}

How to cite this paper: Kaf, R.M., El-Beshbishi, W., Obaya, A.A., Ahmed, R.Z., Helal, K.F., Ramadan, M.SH., Almoregy, A.S., Heggy, I.A. and Harb, O.A. (2019) CRKL and CK2 $\beta$ over Expression Are Independent Predictors of Patients Survival in Endometrioid Endometrial Carcinoma. Open Journal of Obstetrics and Gynecology, 9, 479-493.

https://doi.org/10.4236/ojog.2019.94047

Received: March 18, 2019

Accepted: April 13, 2019

Published: April 16, 2019

Copyright $\odot 2019$ by author(s) and Scientific Research Publishing Inc. This work is licensed under the Creative Commons Attribution International License (CC BY 4.0).

http://creativecommons.org/licenses/by/4.0/

c) (i) Open Access

\begin{abstract}
Context: The prognostic significance of expression of V-Crk avian sarcoma virus CT10 oncogene homolog-like (CRKL) and Protein kinase CK2 $\beta$ in endometroid carcinoma is not fully clarified. Aim: To assess the prognostic values and clinicopathological roles of CRKL and CK2 $\beta$ expression in endometroid carcinoma by correlation their expression levels with clinicopathological parameters, response to therapy, and recurrence of the tumor and patients survival. Settings: Faculty of Medicine, Zagazig University, and Mansoura University. Methods: CRKL and CK2 $\beta$ expressions were evaluated in 50 paraffin blocks EC patients that were followed up for 5 years. The relationship between their level of expressions, clinicopathological criteria and prognosis of patients was analyzed. Statistical analysis used: SPSS 22.0 for windows (SPSS Inc., Chicago, IL, USA) and MedCalc windows (Software bvba 13, Ostend, Belgium). Results: High expression of CRKL and CK was positively correlated with higher grade of the tumor ( $\mathrm{p}=0.004$ and 0.006 respectively), presence of L.N metastases ( $p=0.009$ and 0.003 respectively), presence of distant metastases ( $p=0.029$ and 0.003 respectively) and advanced FIGO stage ( $p<0.001)$, poor response to therapy $(p=0.046$ and 0.005 respectively), higher incidence of recurrence of the tumor after therapy $(\mathrm{p}=0.004$ and 0.048 respectively), higher incidence of cancer progression $\mathrm{p}=0.018$ and 0.044 respectively), poor PFS ( $\mathrm{p}=0.008$ and 0.013 respectively), and OS rates $(\mathrm{p}<$
\end{abstract}


0.001). Conclusion: CRKL and CK2 $\beta$ overexpression in endometrial carcinoma is associated with worse clinicopathological parameters and poor prognosis.

\section{Keywords}

CRKL, CK2 $\beta$, Endometroid Carcinoma, Immunohistochemistry, Prognosis

\section{Introduction}

Endometrial carcinoma is the fourth most commonly diagnosed cancer in females; its incidence is rising and it comes after breast, colorectal and lung cancer. Endometrial carcinoma remains the most fatal female cancer. Endometroid carcinoma is the commonest subtype of endometrial carcinoma and there is a little improvement in treatment strategies and patients' survival which has been achieved recently, highlighting the need for novel targeted therapies and more individualized patients' treatment [1]. Despite the marked improvement of endometrial carcinoma surgical management approaches and the discovering recent adjuvant therapies; the prognosis of such cancer has not been improved. So, it is important to discover new biomarkers that can guide physicians to plan treatment for individual patients who are highly needed. Identifying molecular mediators which are conferring more malignant potential to cells of endometrial carcinoma could be used as novel predictive tumor biomarkers for the risk of progression of endometrial carcinoma [2]. V-Crk avian sarcoma virus CT10 oncogene homolog-like (CRKL) is an adapter proteins family member of the CRK; that has many biological roles, like cell proliferation, adhesion, migration, cell cycle progression, cell survival, and cell invasiveness [3]. CRKL protein was reported to be dysregulated in many malignant cancers [2]. But, its expression pattern in tumor cells, its biological and clinical roles in endometrial carcinoma patients remain uncertain. Protein kinase CK2 is a protein kinase which has more than 300 substrates with multifunction. It is composed of 2 catalytic subunits (CK2a or CK2a') and 2 regulatory $\beta$ subunits. CK2 $\beta$ is involved in normal cell growth, proliferation and differentiation [4]. Dys-regulation of CK2 expression plays a role in the pathogenesis of cancer. CK2 regulates essential cellular processes, many of which are deregulated in cancer cells; cell proliferation, growth, survival, changes cell morphology and it is incriminated in promoting angiogenesis [5]. So, CK2 is considered a suitable target for cancer therapy and there are several CK2 inhibitors which are being tested in clinical trials in targeted therapy against cancer [6]. The significance of expression of CRKL and CK2 $\beta$ in endometrioid carcinoma and relation to its progression and patient's survival are not well clarified.

So in the current study we aimed to assess the prognostic values and clinicopathological roles of CRKL and CK2 $\beta$ expression in endometrioid carcinoma by 
correlation their expression levels with clinicopathological parameters, response to therapy, and recurrence of the tumor and patients survival.

\section{Patients and Methods}

This is a prospective cohort analysis of 50 patients with endometrioid carcinoma who were operated in Gynecology and Obstetrics Department and General Surgery Department, Faculty of Medicine, Zagazig University and Mansoura University. The operation was Total Abdominal Hysterectomy and Bilateral Salpingo-ophrectomy with pelvic lymphadenectomy. Specimens were sent to Pathology department, faculty of medicine Zagazig University, for processing, grading, staging and preparation for further evaluation and immunohistochemical analysis. For grading and staging we have used international-federation-of-gynecology-and-obstetrics' (FIGO) staging system [7]. The routine histological diagnosis was assessed according to the World Health Organization guidelines of endometrial carcinoma classification [8]. Patients were followed up for 5 years in the period from November 2013 to November 2018 for response to therapy, recurrence and survival. Follow up of patients and survival data were obtained from patients files in; Clinical Oncology \& Nuclear Medicine Departments, Faculty of medicine, Zagazig University and Mansoura University and in Medical Oncology Department, Faculty of medicine, Zagazig University. Follow up dead line for all included cases was November 2018. Laboratory tests which were done for all included patients preoperatively, postoperatively and those which were needed during follow-up time were done at Clinical Pathology Department, Faculty of Medicine Zagazig University and Mansoura University. Adjuvant radio-therapy with or without platinum-based chemotherapy were given to patients according to surgical stage and risk stratification of the included patients.

We analyzed correlations between the levels of CRKL and CK2 $\beta$ expressions, clinicopathological and follow up parameters of our patients.

\subsection{Immunohistochemistry Technique of Staining and Evaluation of CRKL and CK2 $\beta$ Expression}

The samples were immersed in ten percent formalin for adequate fixation and were embedded in paraffin. Four- $\mu$ m-thick sections were cut from the blocks. We have used avidin-biotin-peroxidase complex method for immunostaining [9]. We have incubated sections which were cut and put on positively charged slides with anti-CRKL rabbit polyclonal antibody (1:400; ABC242; Millipore, Billerica, USA) and anti-CK2 (monoclonal, 6D5, 1:400 dilution; Santa Cruz Biotechnology, Santa Cruz, CA) at $4^{\circ} \mathrm{C}$ overnight. Counterstaining was made with hematoxylin. We have randomly examined all tumor slides. Five fields were examined in each stained slide, and 100 cells were identified in all fields at $400 \times$ magnification. Immunostaining of CRKL and CK2 $\beta$ was scored by evaluating the staining intensity and the percentage of positive tumor cells semi-quantitatively. The intensity of both CRKL and CK2 $\beta$ staining was given scores from $0-3 ; 0$ 
(no stain), 1 (light stain), 2 (moderate stain) and 3 (strong stain). The percentage were given scores from 0 - 4 when; $0=$ negative, $1(1 \%-25 \%)$ positive, $2(26 \%$ $50 \%)$ positive, $3(51 \%$ - 75\%) positive and 4 (76\% - 100\%) positive tumor cells.

The scores of each tumor sample have been multiplied to reach a final stain score of zero-12. We consider 5 as a cut point to differentiate between CRKL and CK2 $\beta$ low expression which is less than 5 total stain score and tumor samples scoring 5 - 12 were considered to exhibit CRKL and CK2 $\beta$ overexpression [2].

\subsection{Statistical Analysis}

Continuous variables were expressed as the mean \pm SD \& median (range), and the categorical variables were expressed as a number (percentage). Percent of categorical variables were compared using Pearson's Chi-square test or Fisher's exact test when was appropriate. Strength of relationship between IHC of CRKL and CK2 $\beta$ was determined by computing phi coefficient with $(+)$ sign was indicator for direct relationship \& (-) sign was indication for inverse relationship. Recurrence Free Survival (RFS) was calculated as the time from surgery to date of recurrence or the most recent follow-up contact that patient was known as recurrence-free. Progression Free Survival (PFS) was calculated as the time from start of treatment to date of disease progression or the most recent follow-up contact that patient was known as progression-free. Distant Metastasis Free Survival (DMFS) was calculated as the time from diagnosis to date of distant metastasis was detected on imaging or the most recent follow-up contact that patient was known as distant metastasis free. Overall Survival (OS) was calculated as the time from diagnosis to death or the most recent follow-up contact (censored). Stratification of RFS, PFS, DMFS, and OS was done according to CRKL and CK2 $\beta$ expression. These survival rates were graphed using the Kaplan-Meier plot. The $\mathrm{p}$-value $<0.05$ has been considered significant.

\section{Results}

\subsection{Patient Data}

The demographic data of the 50 included patients with endometrioid carcinoma that were included in the study are summarized in Table 1.

Table 1. Demographic data, immunohistochemical markers and outcome of 50 patients with endometrioid carcinoma.

\begin{tabular}{|c|c|c|c|c|c|}
\hline \multirow[t]{2}{*}{ Charactertics } & \multicolumn{2}{|c|}{$\begin{array}{l}\text { All endometrioid } \\
\text { carcinoma patients } \\
\qquad(\mathrm{N}=50)\end{array}$} & \multirow[t]{2}{*}{ Charactertics } & \multicolumn{2}{|c|}{$\begin{array}{l}\text { All endometrioid } \\
\text { carcinoma patients } \\
\qquad(\mathrm{N}=50)\end{array}$} \\
\hline & No. & $\%$ & & No. & $\%$ \\
\hline Age & & & $\underline{\text { FIGO stage }}$ & & \\
\hline$\leq 55$ years & 38 & $76 \%$ & Stage I & 22 & $44 \%$ \\
\hline$>55$ years & 12 & $24 \%$ & Stage II & 10 & $20 \%$ \\
\hline
\end{tabular}




\section{Continued}

\begin{tabular}{|c|c|c|c|c|c|}
\hline$\underline{\text { Size }}$ & & & Stage III & 8 & $16 \%$ \\
\hline$<4 \mathrm{~cm}$ & 17 & $34 \%$ & Stage IV & 10 & $20 \%$ \\
\hline$>4 \mathrm{~cm}$ & 33 & $66 \%$ & & & \\
\hline Grade & & & CRKL & & \\
\hline Grade I & 17 & $34 \%$ & Low & 22 & $44 \%$ \\
\hline Grade II & 18 & $36 \%$ & High & 28 & $56 \%$ \\
\hline Grade III & 15 & $30 \%$ & & & \\
\hline$\underline{\text { LVSI }}$ & & & CK2 $\beta$ & & \\
\hline Absent & 30 & $60 \%$ & Low & 21 & $42 \%$ \\
\hline Present & 20 & $40 \%$ & High & 29 & $58 \%$ \\
\hline Cervical stromal invasion & & & Treatment & & \\
\hline Absent & 22 & $44 \%$ & Surgery & 25 & $50 \%$ \\
\hline Present & 28 & $56 \%$ & $\begin{array}{c}\text { Concurrent } \\
\text { Chemoradiation }\end{array}$ & 15 & $30 \%$ \\
\hline & & & Chemotherapy & 10 & $20 \%$ \\
\hline$\underline{\text { Parametrial extension }}$ & & & Response to CRT & \multicolumn{2}{|c|}{$(\mathrm{N}=25)$} \\
\hline Absent & 32 & $64 \%$ & OAR & 14 & $56 \%$ \\
\hline Present & 18 & $36 \%$ & NR & 11 & $44 \%$ \\
\hline$\underline{\text { Serosal invasion }}$ & & & $\frac{\text { Follow-up duration }}{\underline{\text { (months) }}}$ & & \\
\hline Absent & 32 & $64 \%$ & Mean \pm SD & \multicolumn{2}{|c|}{$36.50 \pm 15.77$} \\
\hline Present & 18 & $36 \%$ & Median (Range) & \multicolumn{2}{|c|}{$38.50(12-60)$} \\
\hline$\underline{\text { Adnexal invasion }}$ & & & $\underline{\text { Recurrence }}$ & \multicolumn{2}{|c|}{$(\mathrm{N}=39)$} \\
\hline Absent & 32 & $64 \%$ & Absent & 33 & $84.6 \%$ \\
\hline Present & 18 & $36 \%$ & Present & 6 & $15.4 \%$ \\
\hline Peritoneal cytology & & & $\underline{\text { Progression }}$ & \multicolumn{2}{|c|}{$(\mathrm{N}=28)$} \\
\hline Negative & 30 & $60 \%$ & Absent & 15 & $53.6 \%$ \\
\hline Positive & 20 & $40 \%$ & Present & 13 & $46.4 \%$ \\
\hline Lymph node & & & $\underline{\text { Metastasis }}$ & \multicolumn{2}{|c|}{$(\mathrm{N}=40)$} \\
\hline Negative & 30 & $60 \%$ & Absent & 32 & $80 \%$ \\
\hline Positive & 20 & $40 \%$ & Present & 8 & $20 \%$ \\
\hline$\underline{\text { Distant metastasis }}$ & & & $\underline{\text { Mortality }}$ & \multicolumn{2}{|c|}{$(\mathrm{N}=50)$} \\
\hline Negative & 40 & $80 \%$ & Alive & 32 & $64 \%$ \\
\hline Positive & 10 & $20 \%$ & Died & 18 & $36 \%$ \\
\hline
\end{tabular}

Categorical variables were expressed as number (percentage). Continuous variables were expressed as mean \pm SD \& median (range).

Patients age was $\leq 55$ years in $38(76 \%)$ and was $>55$ years $12(24 \%)$. Age (years) Mean \pm SD: $52.10 \pm 6.59$, Median (Range): 50.50 (39 - 70). 


\subsection{Immunohistochemical Results}

1) CRKL results Table 2, Figure 1
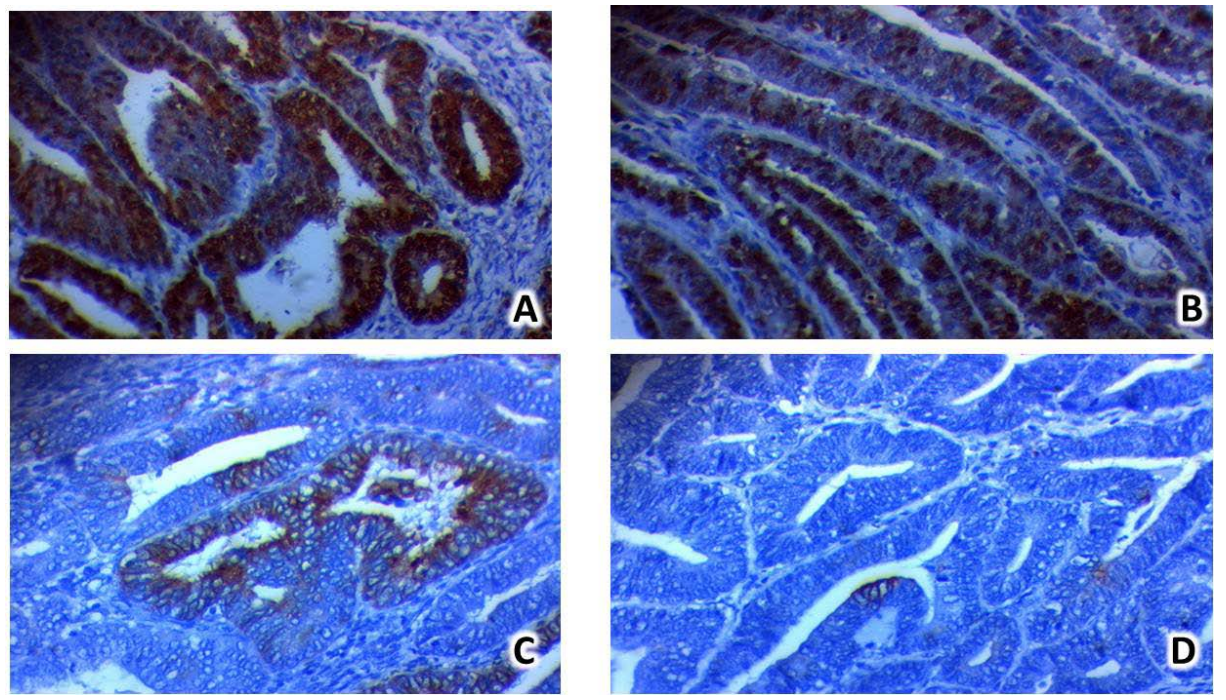

Figure 1. Immunohistochemical expression of CRKL in endometrial carcinoma A; High expression in endometrial carcinoma Grade III, Stage IV 400×, B; High expression endometrioid carcinoma Grade II, stage III 400×, C; low expression in endometrioid carcinoma Grade II, stage II $400 \times$ D; Negative expression in endometrioid carcinoma Grade I, stage I $400 \times$.

Table 2. Relation between clinicopathological features and immunohistochemical staining for CRKL and CK2 $\beta$ in Endometrioid carcinoma patients $(\mathrm{N}=50)$.

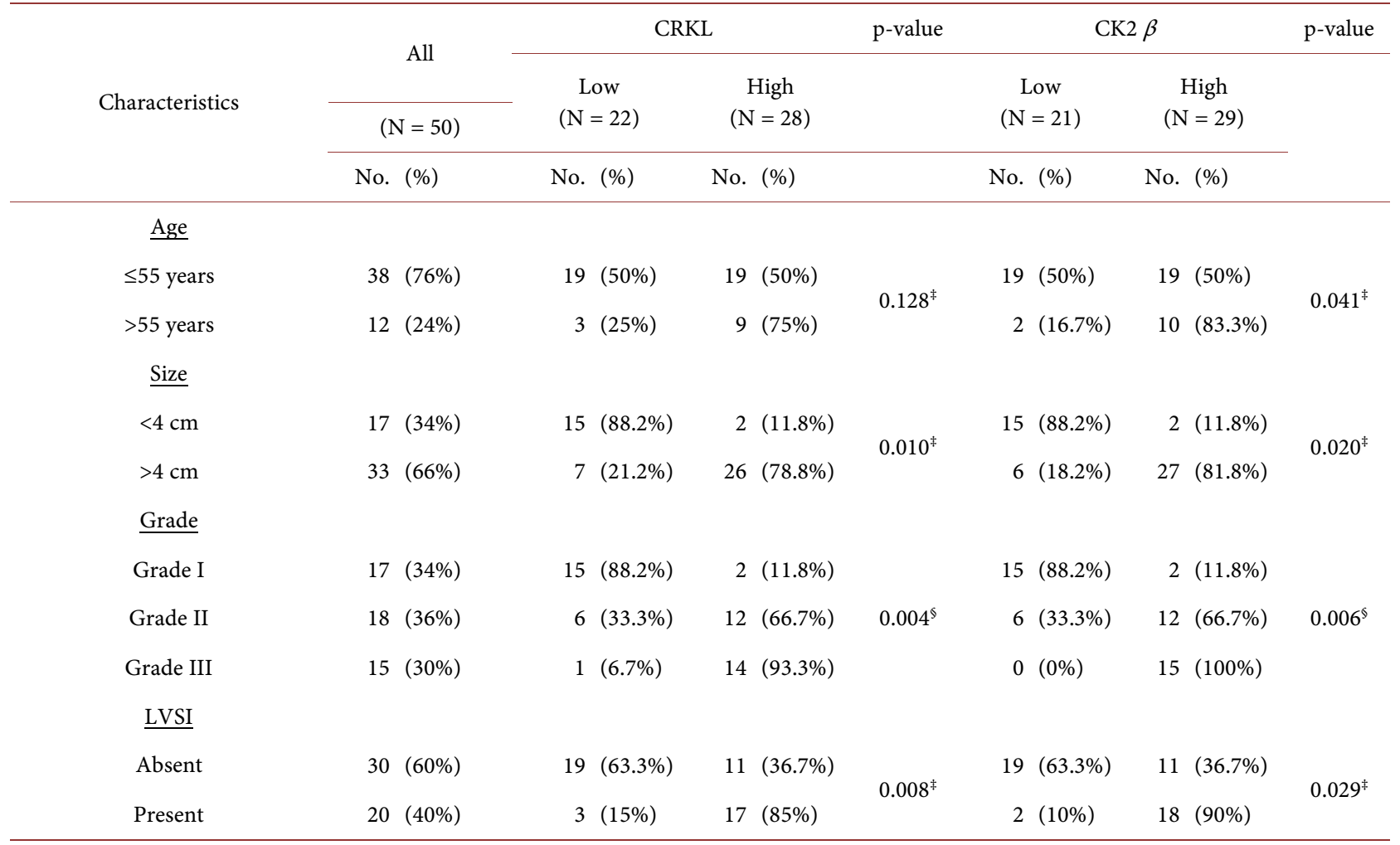




\section{Continued}

$\underline{\text { Extent of myometrial invasion }}$

$\begin{array}{rrrrrrrrr}<50 \% & 17(34 \%) & 15(88.2 \%) & 2(11.8 \%) & & 15(88.2 \%) & 2(11.8 \%) & <0.001^{\ddagger} \\ >50 \% & 33(66 \%) & 7(21.2 \%) & 26(78.8 \%) & & 6(18.2 \%) & 27 & (81.8 \%) & \end{array}$

$\underline{\text { Cervical stromal invasion }}$

$\begin{array}{lrrrrrrrrr}\text { Absent } & 22(44 \%) & 17(77.3 \%) & 5(22.7 \%) & & 17(77.3 \%) & 5(22.7 \%) & 0.007^{\ddagger} \\ \text { Present } & 28(56 \%) & 5(17.9 \%) & 23(82.1 \%) & & 4(14.3 \%) & 24 & (85.7 \%) & \end{array}$

$\underline{\text { Parametrial extension }}$

\section{Absent}

Present

$\underline{\text { Serosal invasion }}$

Absent

Present

$\underline{\text { Adnexal invasion }}$

Absent

Peritoneal cytology

Negative

Positive

Lymph node

Negative
Positive

$\underline{\text { Distant metastasis }}$

Negative
Positive

FIGO stage

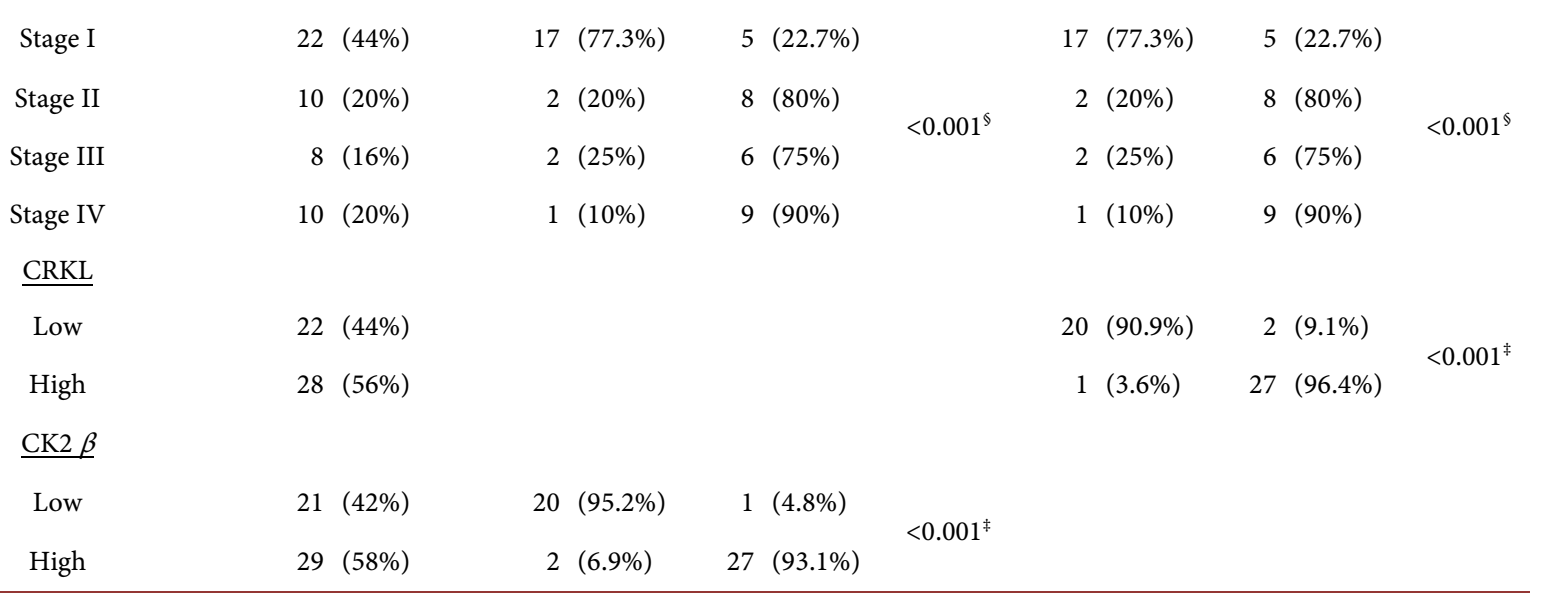

${ }^{\ddagger} \mathrm{Chi}$-square test; ${ }^{\circledR} \mathrm{Chi}$-square test for trend.

Positive expression of CRKL was detected in 28 out of 50 (56\%) cases of endometrioid carcinoma and it was positively correlated with larger size of the tu- 
mor $(\mathrm{p}=0.010)$, higher grade of the tumor $(\mathrm{p}=0.004)$, presence of LVSI $(\mathrm{p}=$ $0.008)$, extent of myometrial invasion $(\mathrm{p}<0.001)$, cervical stromal invasion $(\mathrm{p}=$ $005)$, parametrial invasion ( $\mathrm{p}=0.003)$, adnexal invasion $(\mathrm{p}=0.03)$, L.N metastases $(\mathrm{p}=0.009)$, presence of distant metastases $(\mathrm{p}=0.029)$ and advanced FIGO stage $(\mathrm{p}<0.001)$. There are no significant relations between CRKL expression and age of the patient.

2) CK2 $\beta$ results Table 2, Figure 2

High expression of CK2 $\beta$ was detected in $29(62 \%)$ cases of endometrioid carcinoma and it was positively correlated with larger size of the tumor $(\mathrm{p}=$ $0.020)$, higher grade of the tumor $(p=0.006)$, presence of LVSI $(p=0.029)$, extent of myometrial invasion ( $\mathrm{p}<0.001)$, cervical stromal invasion $(\mathrm{p}=007)$, parametrial invasion $(\mathrm{p}=0.009)$, adnexal invasion $(\mathrm{p}=0.02)$, L.N metastases $(\mathrm{p}=$ $0.003)$, presence of distant metastases (DM) $(\mathrm{p}=0.003)$ and higher FIGO stage $(\mathrm{p}<$ 0.001). There are no significant relations between CK2 $\beta$ expression and age of the patient.

3) Follow up and Survival analysis: Table $3 \&$ Table 4, Figure $3 \&$ Figure 4

High CRKL expression, high CK2 $\beta$ expression was related to poor response to therapy ( $\mathrm{p}=0.046$ and 0.005 respectively), higher incidence of recurrence of the tumor after therapy $(\mathrm{p}=0.004$ and 0.048 respectively), higher incidence of cancer progression $\mathrm{p}=0.018$ and 0.044 respectively), poor PFS $(\mathrm{p}=0.008$ and 0.013 respectively), and OS rates $(\mathrm{p}<0.001)$, We found a direct relationship between CRKL, CK2 $\beta$ Phi: phi coefficient; $+0.878<0.001$ ( $\mathrm{p}<0.001)$.

\section{Discussion}

Endometrioid carcinoma is the commonest subtype of endometrial carcinoma which is considered one of the commonest gynecological cancers worldwide [2].
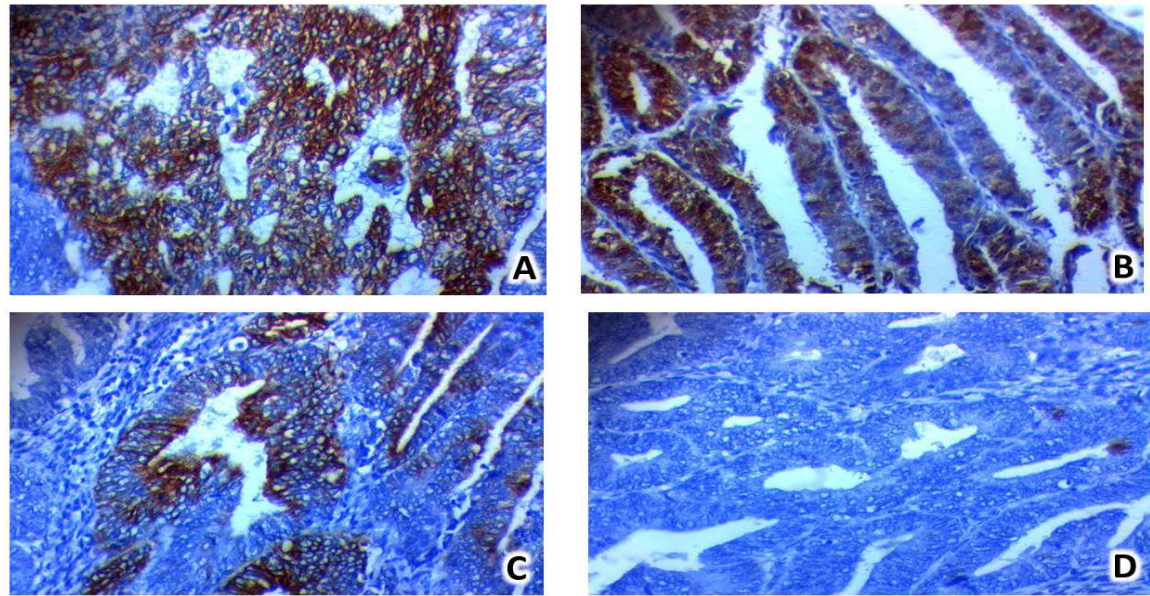

Figure 2. immunohistochemical expression of CK2 $\beta$ in endometrial carcinoma A; High expression in endometrial carcinoma Grade III, Stage IV 400×, B; High expression endometrioid carcinoma Grade II, stage III 400×, C; low expression in endometrioid carcinoma Grade II, stage II 400× D; Negative expression in endometrioid carcinoma Grade I, stage I $400 \times$. 

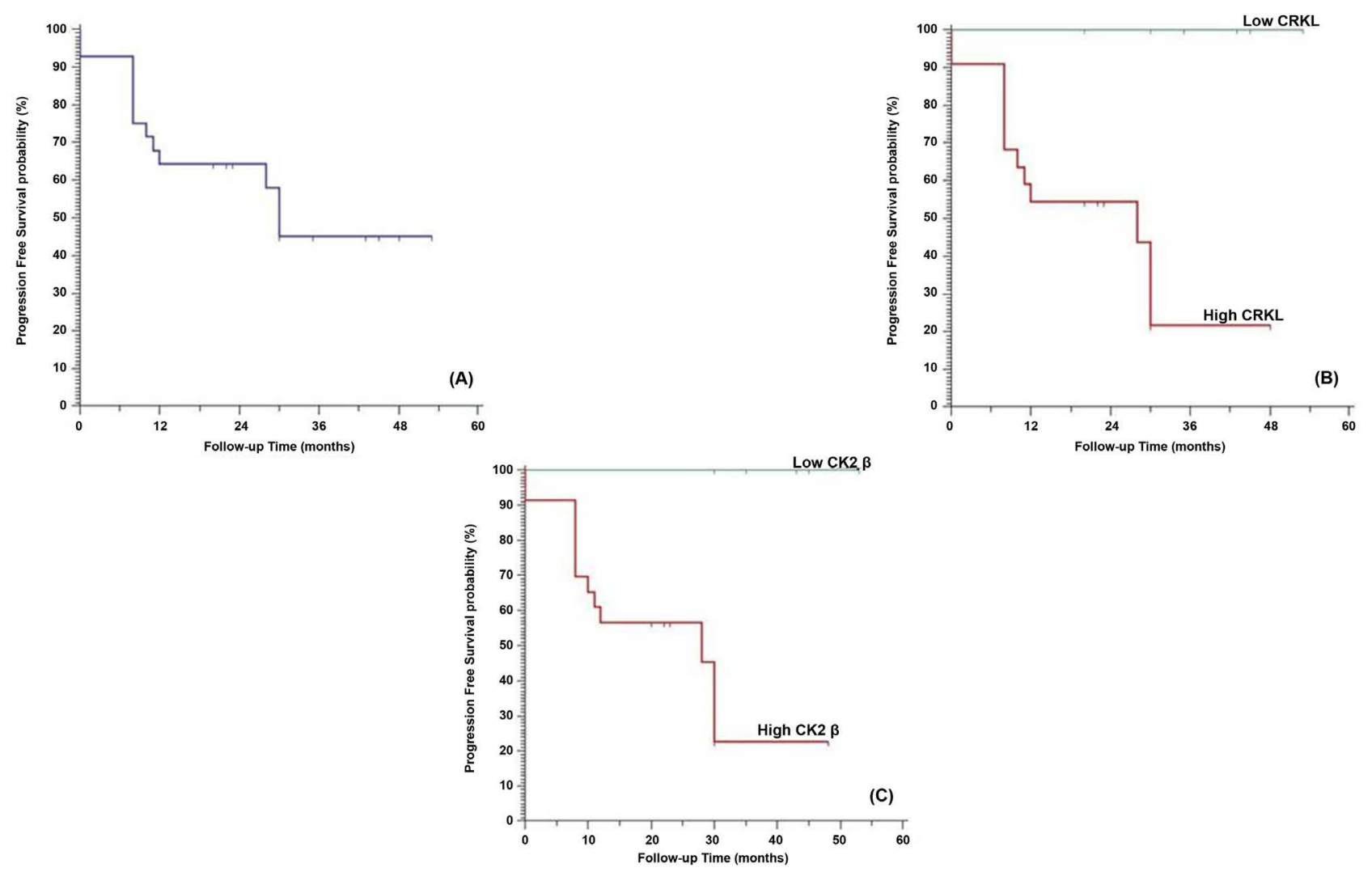

Figure 3. Kaplan Meier plot of Progression Free Survival, (A) All studied patients, (B) Stratified by CRKL (C) Stratified by CK2 $\beta$.
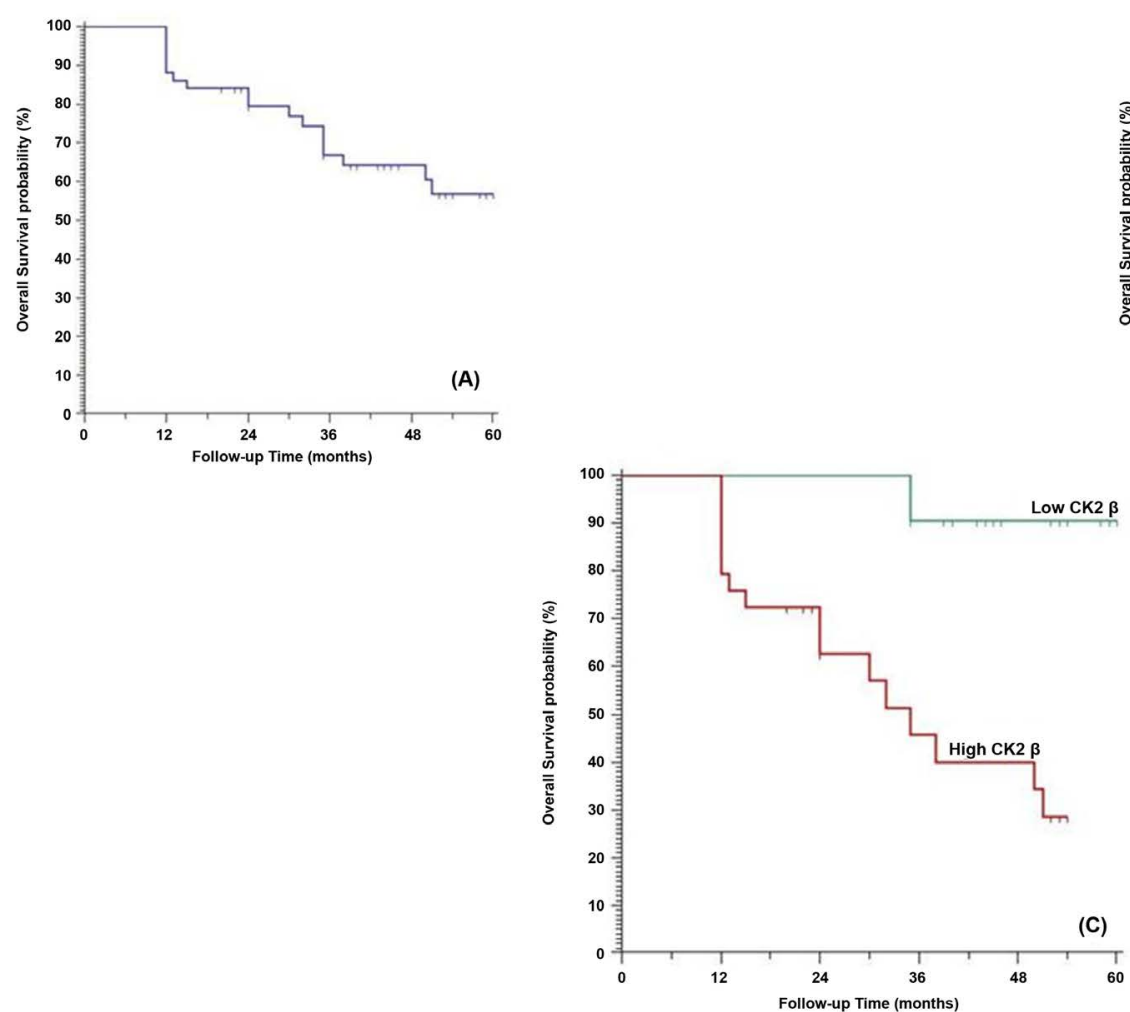

Figure 4. Kaplan Meier plot of Overall Survival, (A) All studied patients, (B) Stratified by CRKL (C) Stratified by CK2 $\beta$. 
Table 3. Relation between immunohistochemical staining for CRKL and CK and outcome in Endometrioid carcinoma patients (N $=50)$.

\begin{tabular}{|c|c|c|c|c|c|c|c|}
\hline \multirow{3}{*}{ Outcome } & \multirow{2}{*}{ All } & \multicolumn{2}{|c|}{ CRKL } & \multirow[t]{3}{*}{ p-value $e^{\ddagger}$} & \multicolumn{2}{|c|}{ CK2 $\beta$} & \multirow[t]{3}{*}{$p$-value } \\
\hline & & Low & High & & Low & High & \\
\hline & No. (\%) & No. (\%) & No. (\%) & & No. (\%) & No. (\%) & \\
\hline Response to CRT & $(\mathrm{N}=25)$ & $(\mathrm{N}=5)$ & $(\mathrm{N}=20)$ & & $(\mathrm{N}=4)$ & $(\mathrm{N}=21)$ & \\
\hline OAR & $14(56 \%)$ & $5(100 \%)$ & $9(45 \%)$ & \multirow{2}{*}{0.046} & $4(100 \%)$ & $10(47.6 \%)$ & \multirow{2}{*}{0.005} \\
\hline NR & $11(44 \%)$ & $0 \quad(0 \%)$ & $11(55 \%)$ & & $0 \quad(0 \%)$ & $11 \quad(52.4 \%)$ & \\
\hline Recurrence & $(\mathrm{N}=39)$ & $(\mathrm{N}=22)$ & $(\mathrm{N}=17)$ & & $(\mathrm{N}=21)$ & $(\mathrm{N}=18)$ & \\
\hline Absent & $33(84.6 \%)$ & $22(100 \%)$ & $11 \quad(64.7 \%)$ & \multirow{2}{*}{0.004} & $20(95.2 \%)$ & $13(72.2 \%)$ & \multirow{2}{*}{0.048} \\
\hline Present & $6(15.4 \%)$ & $0 \quad(0 \%)$ & $6(35.3 \%)$ & & $1(4.8 \%)$ & $5(27.8 \%)$ & \\
\hline Progression & $(\mathrm{N}=28)$ & $(\mathrm{N}=6)$ & $(\mathrm{N}=22)$ & & $(\mathrm{N}=5)$ & $(\mathrm{N}=23)$ & \\
\hline Absent & $15(53.6 \%)$ & $6(100 \%)$ & 9 (40.9\%) & \multirow{2}{*}{0.018} & $5(100 \%)$ & $10(43.5 \%)$ & \multirow{2}{*}{0.044} \\
\hline Present & $13(46.4 \%)$ & $0 \quad(0 \%)$ & $13(59.1 \%)$ & & $0(0 \%)$ & $13(56.5 \%)$ & \\
\hline Metastasis & $(\mathrm{N}=40)$ & $(\mathrm{N}=21)$ & $(\mathrm{N}=19)$ & & $(\mathrm{N}=21)$ & $(\mathrm{N}=19)$ & \\
\hline Absent & $32(80 \%)$ & $19(90.5 \%)$ & $13(68.4 \%)$ & \multirow{2}{*}{0.020} & 19 (90.5\%) & $13(68.4 \%)$ & \multirow{2}{*}{0.030} \\
\hline Present & $8(20 \%)$ & $2(9.5 \%)$ & $6(31.6 \%)$ & & $2(9.5 \%)$ & $6(31.6 \%)$ & \\
\hline Mortality & $(\mathrm{N}=50)$ & $(\mathrm{N}=22)$ & $(\mathrm{N}=28)$ & & $(\mathrm{N}=21)$ & $(\mathrm{N}=29)$ & \\
\hline Alive & $32(64 \%)$ & $20 \quad(90.9 \%)$ & $12(42.9 \%)$ & \multirow{2}{*}{$<0.001$} & 19 (90.5\%) & $13(44.8 \%)$ & \multirow{2}{*}{0.001} \\
\hline Died & $18(36 \%)$ & $2(9.1 \%)$ & $16(57.1 \%)$ & & $2(9.5 \%)$ & $16(55.2 \%)$ & \\
\hline
\end{tabular}

${ }^{\ddagger}$ Chi-square test.

Table 4. Relation between immunohistochemical staining for CRKL and CK2 $\beta$ and survival in endometrioid carcinoma patients $(\mathrm{N}=50)$.

\begin{tabular}{|c|c|c|c|c|c|c|c|}
\hline \multirow{2}{*}{ Outcome } & \multirow{2}{*}{ All } & \multicolumn{2}{|c|}{ CRKL } & \multirow[t]{2}{*}{$p$-value ${ }^{\dagger}$} & \multicolumn{2}{|c|}{$\mathrm{CK} 2 \beta$} & \multirow[t]{2}{*}{ p-value ${ }^{\dagger}$} \\
\hline & & Low & High & & Low & High & \\
\hline Progression Free Survival & $(\mathrm{N}=28)$ & $(\mathrm{N}=6)$ & $(\mathrm{N}=22)$ & & $(\mathrm{N}=5)$ & $(\mathrm{N}=23)$ & \\
\hline $\begin{array}{c}\text { Mean (months) } \\
\quad(95 \% \mathrm{CI})\end{array}$ & $\begin{array}{c}32.11 \text { months } \\
(23.96-40.26)\end{array}$ & $\begin{array}{c}37.67 \text { months } \\
(25.29-50.04)\end{array}$ & $\begin{array}{c}17.54 \text { months } \\
(12.42-22.66)\end{array}$ & 0.008 & $\begin{array}{l}41.20 \text { months } \\
(30.08-52.31)\end{array}$ & $\begin{array}{c}17.65 \text { months } \\
(12.77-22.53)\end{array}$ & 0.013 \\
\hline 1 year PFS & $64.3 \%$ & $100 \%$ & $54.5 \%$ & & $100 \%$ & $56.5 \%$ & \\
\hline 2 year PFS & $64.3 \%$ & $100 \%$ & $54.5 \%$ & & $100 \%$ & $56.5 \%$ & \\
\hline 3 year PFS & $64.3 \%$ & $100 \%$ & $21.8 \%$ & & $100 \%$ & $22.6 \%$ & \\
\hline 4 year PFS & $45 \%$ & - & $21.8 \%$ & & - & $22.6 \%$ & \\
\hline 5 year PFS & - & - & - & & - & - & \\
\hline Overall Survival & $(\mathrm{N}=50)$ & $(\mathrm{N}=22)$ & $(\mathrm{N}=28)$ & & $(\mathrm{N}=21)$ & $(\mathrm{N}=29)$ & \\
\hline $\begin{array}{c}\text { Mean (months) } \\
(95 \% \mathrm{CI})\end{array}$ & $\begin{array}{c}46.13 \text { months } \\
(40.82-51.45)\end{array}$ & $\begin{array}{c}57.61 \text { months } \\
(54.48-60.75)\end{array}$ & $\begin{array}{c}34.18 \text { months } \\
(27.40-40.96)\end{array}$ & $<0.001$ & $\begin{array}{c}57.61 \text { months } \\
(54.48-60.75)\end{array}$ & $\begin{array}{c}34.63 \text { months } \\
(27.94-41.32)\end{array}$ & $<0.001$ \\
\hline 1 year OS & $88 \%$ & $100 \%$ & $78.6 \%$ & & $100 \%$ & $79.3 \%$ & \\
\hline 2 year OS & $79.3 \%$ & $100 \%$ & $61.2 \%$ & & $100 \%$ & $62.8 \%$ & \\
\hline 3 year OS & $66.9 \%$ & $90.5 \%$ & $44.5 \%$ & & $90.5 \%$ & $45.6 \%$ & \\
\hline 4 year OS & $64.4 \%$ & $90.5 \%$ & $39 \%$ & & $90.5 \%$ & $39.9 \%$ & \\
\hline 5 year OS & $56.8 \%$ & $90.5 \%$ & - & & $90.5 \%$ & - & \\
\hline
\end{tabular}

${ }^{\dagger} \log$ rank test. 
Former researchers showed that disordered expression of certain proteins in endometrioid carcinoma tissues could contribute to its progression and malignant behavior [2], but novel bio-markers which are responsible for malignant initiation and progression and that which predict the aggressive behavior have been still urgently needed aiming at discovering novel targeted therapy. CRKL protein was found to be upregulated in many cancers, moreover, CRKL amplification was observed in bronchogenic carcinoma, colorectal cancer and pancreatic cancer [2]. Additionally, CRKL was found to facilitate malignant cells invasion and spread, so, it is correlated with poor patient prognosis [10]. Taken together, these findings revealed that CRKL might be considered an important oncoprotein in malignant development and progression. But, its expression pattern and clinicopathological and prognostic roles in endometrioid carcinoma remain unexplored.

The current study examined CRKL expression in fifty cases of endometrioid carcinoma cells, and CRKL overexpression was positively correlated with higher tumor grade, thus suggesting its association with aggressive malignant behavior. The current data have been found to be in accordance with results of previous reports which confirmed increased CRKL expression in endometrial carcinomas. These results were explained by that CRKL has a role in oncogenesis of malignant tumors through controlling their biological behavior, as proliferation, invasion and spread [2]. Additionally, cell cycle tests revealed that the number of dividing cells which are located in the $S$ phase has increased CRKL expression, which pointed to role of CRKL in cell growth promotion by increasing the G1-S transition [2]. Moreover, cell cycle factors; cyclins E and D1, that have been found to control the progression of cell cycle, were associated with CRKL over expression [11]. The current results were in line with role of CRKL in controlling cell cycle. The association of CRKL with apoptosis is not previously fully clarified. In the present research, increased CRKL expression decreased cisplatin-associated apoptosis in endometrioid carcinoma cells. It was previously reported that, CRKL caused decreased cleavage of caspase-three and caspase-nine, which suggested that CRKL functions as an apoptosis modifier in cells of endometrioid carcinoma [2]. Moreover, CAI et al. [2], showed that high CRKL expression in cancer cells could lead to elevation of the levels of Bcl-2 and survivin, both of them have been found to be responsible for inhibition of apoptosis in cells of the endometrial carcinoma [12] [13]. CAI et al. [2], data support the role of CRKL in controlling malignant cell apoptosis. Our results were in line with results of previous studies that, CRKL are found to be overexpressed in many malignancies and have been found to play essential roles in tumor initiation and progression [14].

Franke et al. [15], provided another explanation of the role of CRKL in cancer progression through stimulation of epithelial-mesenchymal transition that is responsible for cancer spread and metastases.

Our results identified CRKL as novel prognostic marker in endometrioid car- 
cinoma through several mechanisms but as its role in cancer cell apoptosis in such type of cancer is still not fully clarified we chose another marker; CK, which is related to apoptosis in endometrioid carcinoma and assessed its protein expression.

Protein kinase CK2 is a serine/threonine kinase that is distributed in eukaryotic organisms. Several studies have demonstrated the elevated CK2 activity in several malignancies, and changes in the intracellular location with an enhanced nuclear translocation [16]. But its role in endometrioid carcinoma is not well clarified.

We have found that the level of CK2 is correlated with tumor grade, stage, and clinical outcome. This is near results of, Pallares, et al. [16], in endometrial carcinoma and results of $\mathrm{Ma}$ et al. [4], in epithelial ovarian carcinoma.

Dys-regulation of CK2 has been found in several cancers [17] [18]. Taken together results of the current study and results of previous studies revealed that, CK2 overexpression is a risk factor of poor patient prognosis for cancers of many organs and it is considered a potential novel cancer therapeutic target. Similarly Ma et al. [4], proved that CK2 was shown to be overexpressed in malignant ovarian tissue and it plays a role in tumor cell proliferation and apoptosis suggesting its role in cancer progression. Ortega et al. [19], found that is also overexpressed in ovarian cancer tissues and it was associated with lower patient survival rate.

CK2 is found to be involved in protein kinase networks which are responsible for controlling tumor cell growth, proliferation and suppression of apoptosis. Pallares, et al. [16], were able to demonstrate for the first time that CK2 is frequently over expressed in endometrial carcinoma and it played an important role in TRAIL- and Fas-induced apoptosis in such malignancy, by regulating FLIP. Pallares, et al. [16], confirmed their results at the mRNA level by RT-PCR and proved that CK2 expression was associated with increased cell proliferation.

Additionally previous studies proved the requirements for CK2 at various stages of the cell cycle, including G1 phase and the G1/S and G2/M transitions [20] [21]. So CK overexpression is responsible for cancer progression through activation of cell cycle in cancer cells.

The possibility of using targeted therapy against CK was previously studied as Llobet et al. [22], demonstrated that inhibition of CK2 could sensitize endometrial carcinoma to TRAIL-induced apoptosis. TRAIL has been discovered emerged as a promising antineoplastic agent, so, it was found that pharmacological inhibition of CK2 might be considered an interesting target for combination therapies for endometrial carcinomas, as, CK2 was found to have obvious effects on cancer proliferation, apoptosis, migration, and the cell cycle [23], additionally, CK2 is proposed to regulate cell transformation and cancer-associated angiogenesis [6]. There are many CK2 inhibitors which are being tested in clinical trials as targeted therapies for cancer [6] [24].

In addition to its roles in cell cycle progression and inhibition of apoptosis in cancer cells, CK can regulate signaling pathways like (Hh), JAK/STAT, NF- $\kappa$ B, 
and PTEN/PI3K/Akt-PKB. CK2 can activate Wnt signaling by phosphorylating and up-regulating the transcriptional co-factor, $\beta$-catenin [1].

The development of specific inhibitors against CK2 for clinical use is now being paralleled by targeted drug delivery methods, e.g. nanocapsules which are targeted to cancer cells [25].

\section{Summary and Conclusions}

In the current study we found a positive association between both CRKL and CK expression in endometrial carcinoma tissues which both are associated with poor clinicopathological parameters and worse patients survival, and we explained such results that both markers are associated with cell cycle progression and inhibition of apoptosis in such type of cancer which highlighted the possibility of using such markers as targeted therapy in combination with the currently used therapies so as to improve the prognosis of such common cancer.

\section{Conflicts of Interest}

The authors declare no conflicts of interest regarding the publication of this paper.

\section{References}

[1] Fonnes, T., Berg, H., Bredholt, T., et al. (2018) Asparaginase-Like Protein 1 Is an Independent Prognostic Marker in Primary Endometrial Cancer, and Is Frequently Lost in Metastatic Lesions. Gynecologic Oncology, 148, 197-203. https://doi.org/10.1016/j.ygyno.2017.10.025

[2] Cai, L., Wang, H. and Yang, Q. (2017) CRKL Overexpression Promotes Cell Proliferation and Inhibits Apoptosis in Endometrial Carcinoma. Oncology Letters, 13, 51-56. https://doi.org/10.3892/ol.2016.5394

[3] Rhodes, J., York, R.D., Tara, D., et al. (2000) CRKL Functions as a Nuclear Adaptor and Transcriptional Activator in Bcr-Abl-Expressing Cells. Experimental Hematology, 28, 305-310. https://doi.org/10.1016/S0301-472X(99)00148-4

[4] Ma, Z., Wang, X., He, J., Xia, J. and Li, Y. (2017) Increased Expression of Protein Kinase CK2 $\alpha$ Correlates with Poor Patient Prognosis in Epithelial Ovarian Cancer. PLoS ONE, 12, e0174037. https://doi.org/10.1371/journal.pone.0174037

[5] Chua, M., Ortega, C., Sheikh, A., et al. (2017) CK2 in Cancer: Cellular and Biochemical Mechanisms and Potential Therapeutic Target. Pharmaceuticals, 10, 18.

[6] Chua, M.M.J., Lee, M. and Dominguez, I. (2017) Cancer-Type Dependent Expression of CK2 Transcripts. PLOS ONE, 12, e0188854. https://doi.org/10.1371/journal.pone.0188854

[7] Lewin, S.N., Herzog, T.J., Barrena Medel, N.I., et al. (2010) Comparative Performance of the 2009 International Federation of Gynecology and Obstetrics' Staging System for Uterine Corpus Cancer. Obstetrics \& Gynecology, 116, 1141-1149. https://doi.org/10.1097/AOG.0b013e3181f39849

[8] Ali, R.H. and Rouzbahman, M. (2015) Endometrial Stromal Tumours Revisited: An Update Based on the 2014 WHO Classification. Journal of Clinical Pathology, 68, 325-332. https://doi.org/10.1136/jclinpath-2014-202829 
[9] Hsu, S.M., Raine, L. and Fanger, H. (1981) Use of Avidin-Biotin-Peroxidase Complex $(\mathrm{ABC})$ in Immunoperoxidase Techniques: $\mathrm{A}$ Comparison between $\mathrm{ABC}$ and Unlabeled Antibody (PAP) Procedures. Journal of Histochemistry \& Cytochemistry, 29, 577-580. https://doi.org/10.1177/29.4.6166661

[10] Lin, F., et al. (2015) CRKL Promotes Lung Cancer Cell Invasion through ERK-MMP9 Pathway. Molecular Carcinogenesis, 54, E35-E44.

[11] Wang, Y., Dong, Q.Z., Fu, L., et al. (2013) Overexpression of CRKL Correlates with Poor Prognosis and Cell Proliferation in Non-Small Cell Lung Cancer. Molecular Carcinogenesis, 52, 890-899. https://doi.org/10.1002/mc.21935

[12] González-Rodilla, I., Verna, V., Muñoz, A.B., et al. (2011) Expression of the Apoptosis-Related Genes Bcl-2 and p53 in Clinical Samples from Endometrial Carcinoma Patients. Anticancer Research, 31, 4191-4193.

[13] Porichi, O., Nikolaidou, M.E., Apostolaki, A., et al. (2009) BCL-2, BAX and P53 Expression Profiles in Endometrial Carcinoma as Studied by Real-Time PCR and Immunohistochemistry. Anticancer Research, 29, 3977-3982.

[14] Chafik, A. (2018) The Role of CRKL in Breast Cancer Metastasis: Insights from Systems Biology.

[15] Franke, F., Müller, J., Abal, M., et al. (2019) The Tumor Suppressor SASH1 Interacts with the Signal Adaptor CRKL to Inhibit Epithelial-Mesenchymal Transition and Metastasis in Colorectal Cancer. Cellular and Molecular Gastroenterology and Hepatology, 7, 33-53.

[16] Pallares, J., Martinez-Guitarte, J.L., Dolcet, X., et al. (2005) Survivin Expression in Endometrial Carcinoma: A Tissue Microarray Study with Correlation with PTEN and STAT-3. International Journal of Gynecological Pathology, 24, 247-253. https://doi.org/10.1097/01.pgp.0000163849.37129.d4

[17] Bae, J.S., Park, S.H., Kim, K.M., et al. (2015) CK2alpha Phosphorylates DBC1 and Is Involved in the Progression of Gastric Carcinoma and Predicts Poor Survival of Gastric Carcinoma Patients. International Journal of Cancer, 136, 797-809.

[18] Shimada, K., Anai, S., Marco, D.A., et al. (2011) Cyclooxygenase 2-Dependent and Independent Activation of Akt through Casein Kinase 2alpha Contributes to $\mathrm{Hu}-$ man Bladder Cancer Cell Survival. BMC Urology, 11, 8.

https://doi.org/10.1186/1471-2490-11-8

[19] Ortega, C.E., Seidner, Y. and Dominguez, I. (2014) Mining CK2 in Cancer. PLoS ONE, 9, e115609. https://doi.org/10.1371/journal.pone.0115609

[20] Pepperkok, R., Lorenz, P., Ansorge, W., et al. (1994) Casein Kinase-II Is Required for Transition of G0/G1, Early G1, and G1/S Phases of the Cell-Cycle. The Journal of Biological Chemistry, 269, 6986-6991.

[21] Lorenz, P., Pepperkok, R., Ansorge, W., et al. (1993) Cell Biological Studies with Monoclonal and Polyclonal Antibodies against Human Casein Kinase-II Subunit-Beta Demonstrate Participation of the Kinase in Mitogenic Signaling. The Journal of Biological Chemistry, 268, 2733-2739.

[22] Llobet, D., Eritja, N., Encinas, M., et al. (2008) CK2 Controls Trail and Fas Sensitivity by Regulating FLIP Levels in Endometrial Carcinoma Cells. Oncogene, 27, 2513-2524. https://doi.org/10.1038/sj.onc.1210924

[23] Prudent, R., Moucadel, V., Nguyen, C.H., et al. (2010) Antitumor Activity of Pyridocarbazole and Benzopyridoindole Derivatives That Inhibit Protein Kinase CK2. Cancer Research, 70, 9865-9874.

[24] Cozza, G. and Pinna, L.A. (2016) Casein Kinases as Potential Therapeutic Targets. 
Expert Opinion on Therapeutic Targets, 20, 319-340.

[25] Unger, G.M., Kren, B.T., Korman, V.L., Kimbrough, T.G., Vogel, R.I., Ondrey, F.G., Trembley, J.H. and Ahmed, K. (2014) Mechanism and Efficacy of Sub-50-nm Tenfibgen Nanocapsules for Cancer Cell-Directed Delivery of Anti-CK2 RNAi to Primary and Metastatic Squamous Cell Carcinoma. Molecular Cancer Therapeutics, 13, 2018-2029. https://doi.org/10.1158/1535-7163.MCT-14-0166 